Annales Geophysicae (2001) 19: 289-302 (C) European Geophysical Society 2001

(5)

\title{
Solar and auroral evidence for an intense recurrent geomagnetic storm during December in AD 1128
}

\author{
D. M. Willis ${ }^{1, *}$ and F. R. Stephenson ${ }^{2}$ \\ ${ }^{1}$ Space and Astrophysics Group, Department of Physics, University of Warwick, Coventry CV4 7AL, UK \\ *Also Honorary Research Associate, Rutherford Appleton Laboratory, Chilton, Didcot, Oxon OX11 0QX, UK; and Visiting \\ Reader in Physics, University of Sussex, Falmer, Brighton BN1 9QH, UK \\ ${ }^{2}$ Department of Physics, University of Durham, Durham DH1 3LE, UK
}

Received: 4 August 2000 - Revised: 9 January 2001 - Accepted: 19 January 2001

\begin{abstract}
The earliest known drawing of sunspots appears in The Chronicle of John of Worcester, which was compiled in the first half of the twelfth century. In this medieval chronicle, the Latin text describing the sunspots is accompanied by a colourful drawing, albeit idealised, which shows the apparent positions and sizes of two sunspots on the solar disk. The date of this observation of sunspots from Worcester, England is firmly established as AD 1128 December 8. Assuming that the drawing was prepared fairly carefully, the angular diameters of the two sunspots are at least about 3 arcmin and 2 arcmin in the northern and southern hemispheres, respectively. Similarly, the heliographic latitudes of both sunspots are within the approximate range of $25^{\circ}-35^{\circ}$. About five days after this observation of sunspots on the solar disk, on the night of AD 1128 December 13, a red auroral display was observed from Songdo, Korea (the modern city of Kaesong). This auroral observation was recorded in the Koryo-sa, the official Korean chronicle of the period. In addition, five Chinese and five Korean descriptions of auroral displays were recorded in various East-Asian histories between the middle of AD 1127 and the middle of AD 1129. The ten oriental auroral records in this particular interval correspond to six distinct auroral events, which provide evidence for recurrent, though possibly intermittent, auroral activity on a timescale almost exactly equal to the synodic-solar-rotation period (approximately 27 days). The six distinct auroral events were apparently associated with two series of recurrent geomagnetic storms, both of which were sufficiently intense to produce mid-latitude auroral displays in East Asia. These ancient solar and auroral observations are interpreted in terms of present-day understanding of solar-terrestrial physics. Contemporary ground-based and satellite measurements during the last few decades have indicated that recurrent geomagnetic storms are usually a feature of the declining phase of the solar cycle. In addition, the strength of such recurrent geomagnetic storms has been classified as moderate rather than intense. The recurrent geomagnetic storms occurring dur-
\end{abstract}

Correspondence to: D. M. Willis (d.m.willis@ $@$ rl.ac.uk) ing the interval AD 1127-1129 must have been sufficiently intense to produce mid-latitude auroral displays over China and Korea, some of which appeared or extended south of the observing site. This last statement remains true even after proper allowance is made for the fact that during the twelfth century, the north geomagnetic pole was probably situated at the usual high geographic latitude, but in the same geographic longitude range as East Asia. Therefore, it may be inferred that the two series of intense recurrent geomagnetic storms occurred near a medieval maximum in the "elevenyear" solar cycle. Moreover, the overall level of solar activity appears to have been especially high at the end of the second decade of the twelfth century.

Key words. Magnetospheric physics (auroral phenomena; storms and substorms) - Solar physics, astrophysics and astronomy (photosphere and chromosphere)

\section{Introduction}

Stephenson and Willis (1999) have discussed the earliest known drawing of sunspots, which appears in The Chronicle of John of Worcester (Darlington et al., 1995; McGurk, 1998). This medieval chronicle contains records of various celestial phenomena, such as eclipses of the Sun and Moon, comets, meteor showers and aurorae. Of particular interest to solar-terrestrial physics is a description of two sunspots that were seen on December 8 in the year AD 1128 from Worcester, England $\left(52.2^{\circ} \mathrm{N}, 2.2^{\circ} \mathrm{W}\right)$. In the solitary manuscript (probably contemporary) containing this account, the Latin text is accompanied by a colourful drawing, albeit somewhat idealised, that shows the apparent positions and sizes of the two sunspots on the solar disk. The drawing and the surrounding Latin text are reproduced in Fig. 1. This idealised drawing appears to be the earliest known illustration of sunspots on the solar disk, despite the fact that unaided-eye observations of sunspots had been recorded in Chinese dynastic histories for more than 1000 years prior to AD 1128. 
Stephenson and Willis (1999) have provided further historical background information that clarifies both the cultural and scientific importance of this first illustration of sunspots. Moreover, independent historical records from China and North China (at that time, two separate empires) indicate that a single sunspot was seen on the solar disk on AD 1129 March 22. The date of these Chinese and North Chinese sightings of a single sunspot is almost four synodic-solarrotation periods after the English sighting of two sunspots on AD 1128 December 8, which suggests that the same sunspot (or dense sunspot group) may have been observed on both occasions. In recent times, large sunspot groups have been known to persist for several solar rotations.

The scientific importance of the observation of two sunspots on AD 1128 December 8 is greatly enhanced, however, by the existence of an observation of the aurora borealis only five days later, on the night of AD 1128 December 13 (Yau et al., 1995). This particular auroral observation was recorded in the official Korean chronicle of the period, the Koryo-sa. The original historical record, together with adjacent entries in the chronicle, is reproduced in Fig. 2. In general terms, a delay of about five days between central meridian passage of an active solar region, as manifested by a complex sunspot group, and the occurrence of mid-latitude auroral displays is quite typical (Crooker and Cliver, 1994). Moreover, between the middle of AD 1127 and the middle of AD 1129, five Chinese and five Korean descriptions of auroral displays were recorded in East-Asian histories (Beijing Observatory, 1988; Yau et al., 1995). No auroral observations were recorded in Japanese histories during this interval (see also Matsushita, 1956). The ten available oriental auroral records provide evidence for recurrent, albeit intermittent, auroral activity on a timescale almost exactly equal to the synodic-solar-rotation period (approximately 27 days).

The observation of two sunspots from Worcester, England on AD 1128 December 8 is described in Sect. 2. The subsequent observation of a red auroral display from Songdo, Korea, during the night starting on AD 1128 December 13, is described in Sect. 3. Evidence for recurrent auroral activity between the middle of AD 1127 and the middle of AD 1129, gleaned from Chinese and Korean histories, is presented in Sect. 4. The scientific interpretation of these medieval solar and auroral observations is discussed in Sect. 5 and the conclusions are presented in Sect. 6.

Throughout this paper we have adopted Wade-Giles romanisations for book titles and names of medieval Chinese cities. However, for names of modern cities (e.g. Beijing and Hangzhou) we have used Pinyin, which has become standard practice in recent years.

\section{Observation of sunspots on AD 1128 December 8}

The Chronicle of John of Worcester was compiled during the first half of the twelfth century (Darlington et al., 1995; McGurk, 1998). The most important manuscript of this chronicle, which contains the sunspot drawing and the accompa- nying written description, is in the archives of Corpus Christi College, Oxford (MS 157). For the period from AD 1128 to 1140 , this manuscript contains much unique information and is possibly written in the hand of John of Worcester himself (Darlington et al., 1995, pp. xxi, xxix-xxxv; McGurk, 1998, p. xix).

The entry describing the observation of two sunspots (or two dense sunspot groups) on AD 1128 December 8 in England, as translated by McGurk (1998, p. 183), is as follows:

[1128] "In the third year of Lothar, emperor of the Romans, in the twenty-eighth year of King Henry of the English, in the second year of the 470th Olympiad, seventh indiction, twenty-fifth moon, on Saturday, 8 December, there appeared from the morning right up to the evening two black spheres against the sun (quasi due nigre pile infra solis orbitam). The first was in the upper part and large, the second in the lower and small, and each was directly opposite the other as this diagram shows" (Corpus Christi College MS 157, folio 380, lower half).

As noted by Stephenson and Willis (1999), the date of this observation of sunspots on the solar disk is firmly established. The reference to the third (full) year of Lothar, King of Germany, and the twenty-eighth (full) year of Henry (I), King of England, is consistent with the year AD 1128, as is the reference to the seventh indiction (a 15-year fiscal period). However, John of Worcester has miscalculated by 26 years when giving the date in terms of the Olympiads (a secondary year count). Nevertheless, a date in AD 1128 is confirmed by the fact that December 8 was indeed a Saturday in that particular year. John of Worcester has also made a mistake in giving the day of the lunar month; December 8 was the 15th rather than the 25th day. This latter discrepancy could be the result of a scribal error or, alternatively, simply a lack of the necessary astronomical knowledge, which was not uncommon among medieval European chroniclers. McGurk (1998) mentions (in a footnote) that the sunspots observed at Worcester were not recorded elsewhere. There is, in fact, no known record of any other sunspot observation in either occidental or oriental histories (Wittmann and $\mathrm{Xu}$, 1987; Yau and Stephenson, 1988) from essentially the beginning of AD 1122 (oriental sunspot observation on January 10) until the spring of AD 1129 (oriental sunspot observation on March 22).

However, it may well be highly significant that observations of a single sunspot from both China and North China on AD 1129 March 22 (Yau and Stephenson, 1988), occurred approximately four synodic-solar-rotation periods after the sighting of two sunspots from Worcester, England on AD 1128 December 8. The relevant oriental historical records originate from two separate empires, one which may be termed China proper (the territory ruled by the native Chinese Sung dynasty) and one in northern China (the territory conquered by the invading Chin dynasty). Presumably, the 
สĭ Q.

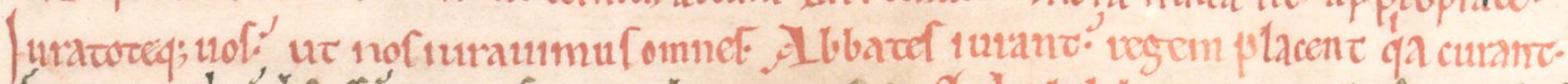

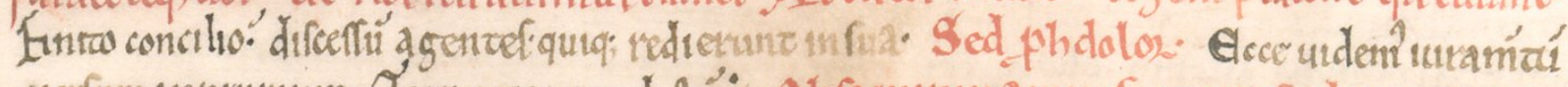

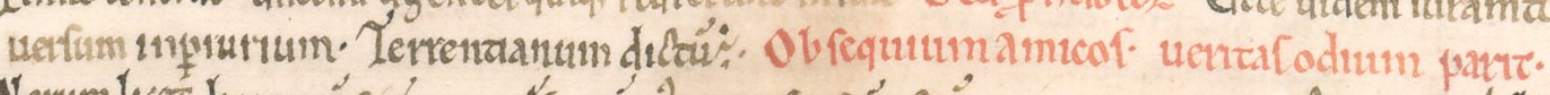

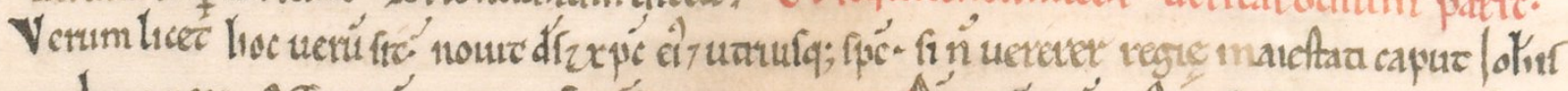

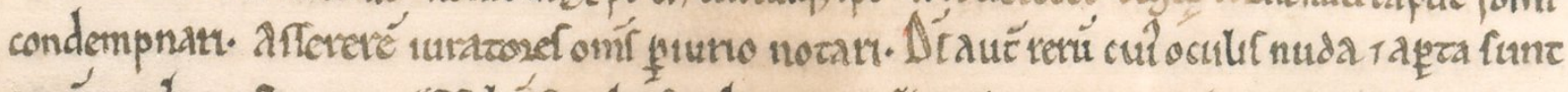

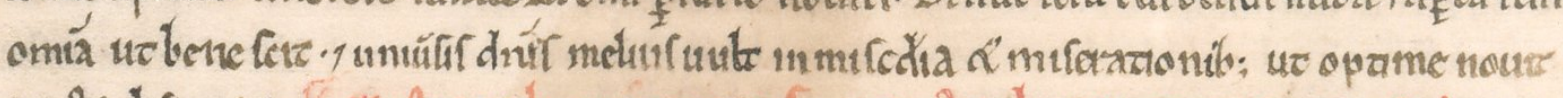

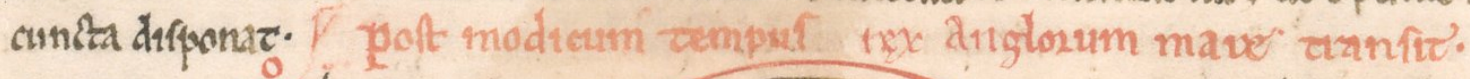

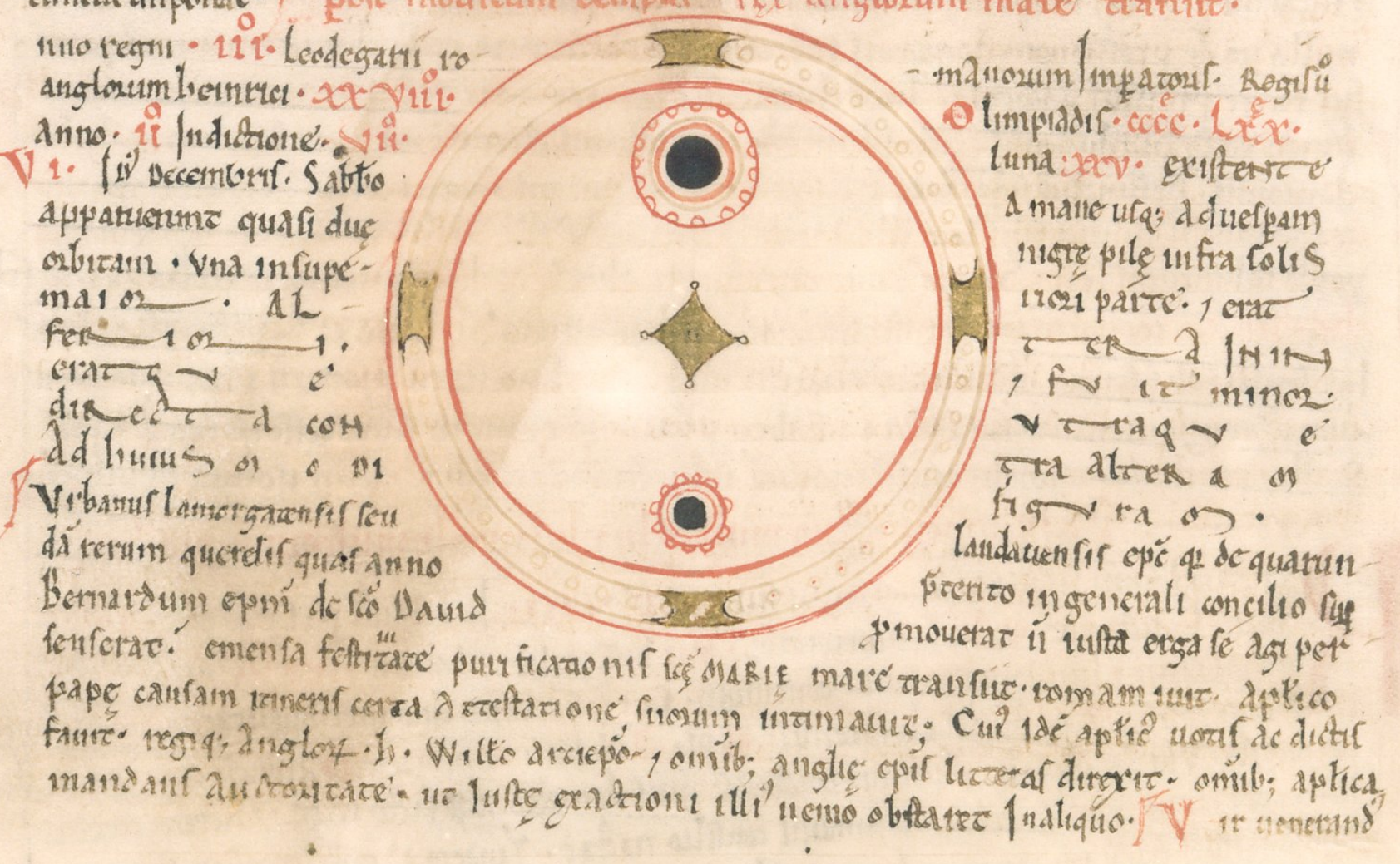

Fig. 1. The earliest known drawing of sunspots, which appears in The Chronicle of John of Worcester (Darlington et al., 1995; McGurk, 1998). This drawing shows the apparent positions and sizes of two sunspots that were observed on AD 1128 December 8 from Worcester, England. Part of the surrounding Latin text describes the two sunspots and also presents historical information that enables this medieval sunspot observation to be precisely dated. A translation of the relevant part of the Latin text is presented in Sect. 2.

Chinese and North Chinese observations of the sunspot on AD 1129 March 22 were independent. Around this time, the Jurchen tribes from Manchuria, who had established the Chin dynasty in AD 1115, overran the northern half of the Sung empire. They captured its capital Pien (modern name Kaifeng) in January of AD 1127 and the emperor was taken into exile. The Sung court fled south and the dynasty never regained its lost territory. A new Sung emperor was enthroned at Ying-t'ien (close to the modern city of Shangqiu) in June of that year.

The two sunspot records (Sung-shih, 25, 52) from China proper (capital: Hang-chou, later named Lin-an, the modern city of Hangzhou) and the single record (Chin-shih, 20) from North China (principal capital: Shang-ching in Inner Mongolia, the modern city of Acheng) state that "there was a black spot within the Sun" on AD 1129 March 22. Both the "Annals" (Sung-shih, 25) and the "Astronomical Treatise" (Sungshih, 52) from China proper state further that "the black spot within the Sun died away" on AD 1129 April 14. Moreover, neither of these Chinese histories mentions sunspot sightings on any other day in the interval between March 22 and April 14. Since the same sunspot cannot have been seen continuously for 24 days, these particular Chinese records imply that more than one large sunspot (or dense sunspot group) 


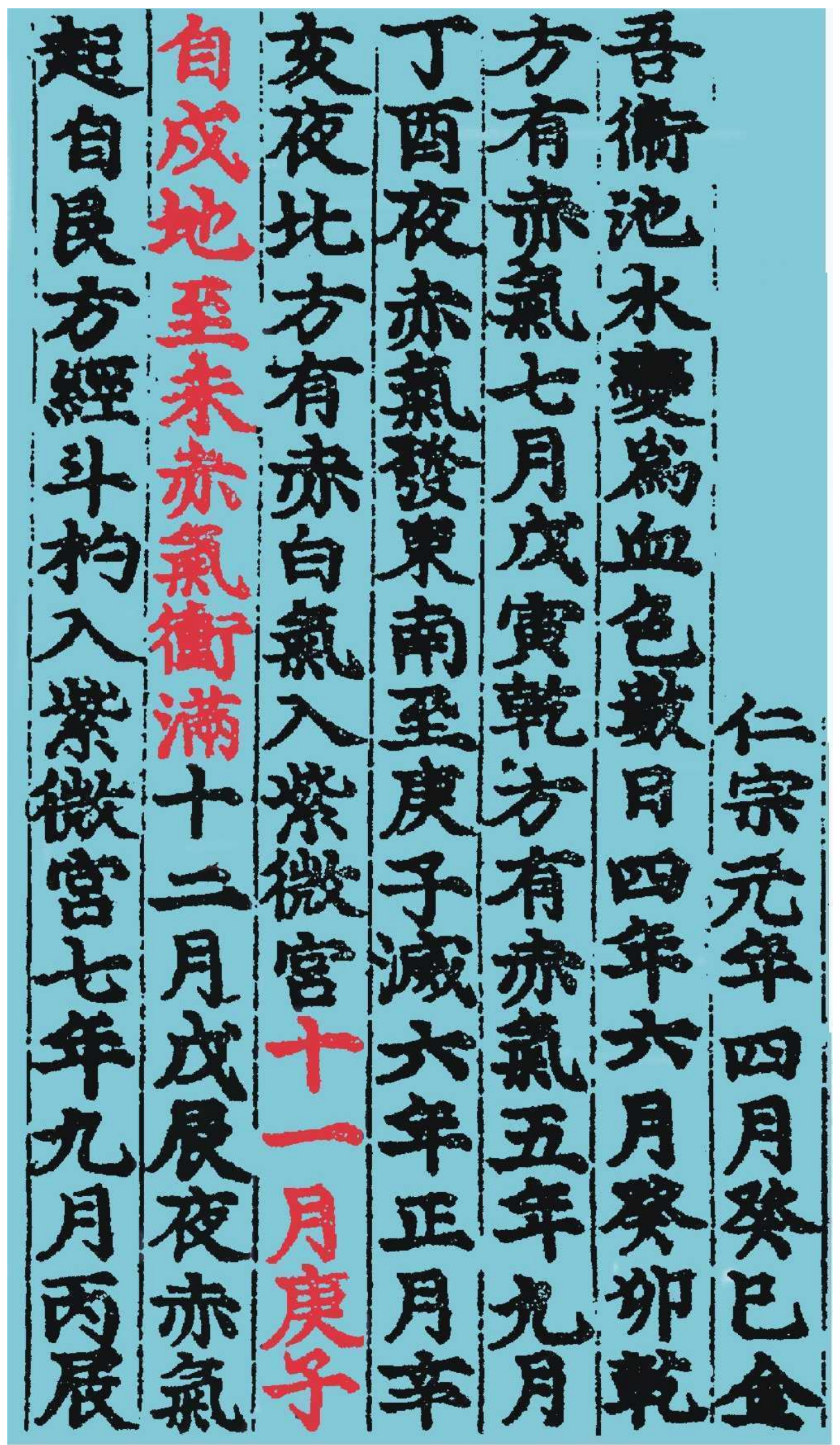

Fig. 2. Description of an observation of the aurora borealis on the night of AD 1128 December 13 from Songdo, Korea (Kaesong), as recorded in the Koryo-sa (the official Korean chronicle of the period). The Chinese characters coloured red in the fifth and sixth columns from the right describe a red vapour that "soared and filled the sky" from the north-west to the south-west and also present calendrical information that enables this medieval auroral observation to be precisely dated (Yau et al., 1995). A translation of the relevant part of the Chinese text is presented in Sect. 3. Several other aurorae observed in AD 1126, 1127, 1128 and 1129 are also described on this page from the Koryo-sa (see also Table 1). 
was observed during the inclusive interval AD 1129 March 22 to April 14.

Therefore, it is quite likely that the level of solar activity was pronounced throughout this interval, although the seasonal variation of suitable atmospheric viewing conditions in East Asia tends to favour the detection of sunspots during the spring (Willis et al., 1980, 1988). It is also possible that one of the two sunspots observed on AD 1128 December 8 from Worcester, England survived for a further 104 days to be observed again on AD 1129 March 22 from both Hangchou in China and Shang-ching in North China. This latter possibility follows from the fact that a large sunspot would certainly be visible with the naked eye (in the absence of obscuring cloud cover) up to about six days before (or after) its central meridian passage. Unfortunately, none of the oriental records gives any indication of the position on the solar disk of either the single sunspot seen on AD 1129 March 22 or the different single sunspot seen on AD 1129 April 14.

The drawing in the original manuscript version of The Chronicle of John of Worcester, which was first published by Darlington et al. (1995, p. xxxiii), is shown in Fig. 1. This drawing is surrounded by the Latin text, most of which describes the sunspots. The artistic adornment in Fig. 1 (particularly of the sunspots themselves) hinders a proper scientific interpretation of the drawing. Nevertheless, it should be noted that the main visual features of the sunspots (heliographic positions and relative sizes) are in good agreement with the details recorded in the accompanying Latin text. Indeed, the written description of the positions and sizes of the two sunspots, together with the clear statement that they were visible "from the morning right up to the evening", provides a remarkably detailed medieval record. Moreover, although the sketch is clearly idealised, there appears to have been quite a deliberate attempt, more than eight-and-a-half centuries ago, to depict two sunspots of different sizes, which are distinctly off-centre in the northern and southern solar hemispheres.

To obtain approximate quantitative estimates of the sizes of the two sunspots, it is assumed that each of the two areas coloured black represents the total (umbral plus penumbral) area of the sunspot, and that the outermost red circle represents the solar limb. With these basic assumptions, the angular diameters of the sunspots in the northern and southern hemispheres of the Sun would have been about 3 arcmin and 2 arcmin, respectively (Stephenson and Willis, 1999). Any realistic change in the basic assumptions, such as a smaller solar disk corresponding to the inner red circle encompassing both sunspots, inevitably results in even larger estimates for the angular diameters of the two sunspots. The minimum diameter of a sunspot that can be detected by the human eye, without the aid of a telescope, is almost certainly less than 1 arcmin (Willis et al., 1996, and references cited therein). Therefore, with the implicit assumption that Fig. 1 was drawn approximately to scale (perhaps by prolonged observation through haze, since the solar altitude at Worcester in December was no more than $15^{\circ}$ at noon), both black sunspots depicted in this drawing would have been easily ob- servable with the naked eye.

The assumption that Fig. 1 was drawn approximately to scale also leads to estimates of the heliographic latitudes of the two sunspots, although it should be noted that there is no indication of the specific time of day to which the drawing refers. The position angle of the Sun's rotational axis with respect to the vertex (perpendicular to the horizontal), as viewed from Worcester (geographic latitude $52.2^{\circ} \mathrm{N}$ ), would have varied considerably during the course of the day. On December 8 (in AD 1128), this angle would have changed from about $46^{\circ} \mathrm{E}$ at sunrise (08:00 $\left.\mathrm{LT}\right)$, to $14^{\circ} \mathrm{E}$ at noon (12:00 LT), and eventually to $18^{\circ} \mathrm{W}$ at sunset (16:00 LT). Therefore, assuming a fairly careful drawing, the heliographic latitudes of the two sunspots would have been within the approximate range of $25^{\circ}-35^{\circ}$ (in the northern and southern hemispheres). From a statistical viewpoint, sunspots are more likely to be observed in this latitude range soon after sunspot minimum (according to the so-called "butterfly diagram"), whereas they are more likely to have the estimated sizes $(\approx 2-3$ arcmin) near sunspot maximum (Royal Greenwich Observatory, 1955; Phillips, 1992). However, it is not unknown for giant sunspot groups (e.g. 1926 January 24, 1937 July 28 and 1947 April 7) to exist at relatively high heliographic latitudes $\left(>20^{\circ}\right)$ near sunspot maximum (Royal Greenwich Observatory, 1955).

Moreover, as noted by Stephenson and Willis (1999), ample allowance should be made for the use of artistic licence in the preparation of the early sunspot drawing presented in Fig. 1. For some indication of the possible degree of contemporaneous artistic licence, the interested reader is referred to the eight different drawings of the large partial solar eclipse of AD 1153 January 26, as found in the chronicles of the monastery at Erfurt, Germany (Stephenson, 1997; see Fig. 11.9). It is conjectured here that the sizes of the sunspots (or dense sunspot groups) might be slightly more realistic than their heliographic latitudes, although both the latitudes and the sizes could well have been exaggerated somewhat for the purpose of visual impact. Nevertheless, it still seems likely that Fig. 1 depicts the positions of the two sunspots at a time when they were fairly close to the central meridian, as was certainly the situation for much of the time between noon and sunset. Stated alternatively, it seems unlikely that Fig. 1 depicts the situation near dawn, if only because John of Worcester might well have spent some time assimilating such an unusual observation before attempting an entirely novel drawing (or perhaps a preliminary sketch). Irrespective of the actual time of day to which the sunspot drawing refers, the configuration of the two large sunspots shown in Fig. 1 probably implies that at least one active solar region was reasonably close to the central meridian on AD 1128 December 8 (i.e. within perhaps $\pm 40^{\circ}$ of heliographic longitude). 


\section{Observation of the aurora borealis on AD 1128 De- cember 13}

The observation of the aurora borealis on AD 1128 December 13 is taken directly from the new catalogue of auroral observations from China, Korea and Japan (193 BC - AD 1770) published by Yau et al. (1995). This catalogue has, as its nucleus, the work of both Keimatsu (1970-1976) and Dai and Chen (1980). However, an independent search of East Asian history was also undertaken in the process of compiling the new catalogue. Willis and Stephenson (2000) have discussed, in detail, the background information required for a proper interpretation of the oriental auroral observations presented in this catalogue. For completeness, those facts that are strictly relevant to the present paper are briefly repeated here, immediately after the presentation of the Korean auroral record for AD 1128 December 13. However, some of these facts are more relevant to the discussion of the nine additional oriental auroral records, as presented in Sect. 4.

The entry describing the observation of the aurora borealis from a site in Korea on AD 1128 December 13 may be translated as follows:

1128 December 13 [Korea, Songdo] King Injong ...6th year ...11th month, day keng-tzu (37). "From the NW to SW, a red vapour soared and filled the sky." (Koryo-sa, 53) [NB. Although not stated, this was the 20th day of the lunar month.]

The Korean book title is presented in italics (Koryo-sa), together with the appropriate chapter number (53). The text, along with several other auroral entries in the early years of King Injong, is illustrated in Fig. 2; the Chinese characters coloured red in the fifth and sixth columns from the right provide the greater part of the preceding English translation (beginning with the month).

Following Willis and Stephenson (2000), it is assumed that the actual location, at which a Chinese or Korean auroral observation was made, is in the vicinity of the imperial or royal capital, unless there is evidence to the contrary. For example, it is assumed that the Korean auroral observation on AD 1128 December 13 was made at Songdo (the modern city of Kaesong), the Korean capital for almost the entire period from AD 936 until 1392. The place name Songdo is added within square brackets after the country name in the quoted record (i.e. [Korea, Songdo]). As noted previously, the political situation in China around this period was extremely complex. Presumably, the Sung auroral observations during September in AD 1127 (see Table 1) were made at Yingt'ien, but at this turbulent period there can be no certainty about the exact location.

The Chinese calendar, which was luni-solar, was adopted with little change in Korea. However, in both countries, years were numbered relative to the reign of the appropriate ruler. In both China and Korea, most years contained twelve lunar months, each with a length 29 or 30 days. Every three years or so, an intercalary month was inserted in order to keep the calendar in step with the seasons. Intercalation was not always practised simultaneously in China and Korea, but differences were usually slight. Days were sometimes counted from the start of each lunar month. However, a 60-day (sexagenary) cycle was also adopted. This cycle, which covered a little over two lunar months, was independent of any astronomical parameter. Its regular use materially assists in the conversion of dates to the Julian calendar (the dates discussed in this paper are well before AD 1582 October 5). A computer program has been devised by the authors to effect rapid date conversion to the Julian calendar.

Only one of the oriental auroral records quoted in this paper mentions a specific time of night, namely the evening of AD 1127 September 22 (see Table 1). Azimuthal directions were usually very crude, no more than N, NE, E, SE, S, SW, $\mathrm{W}$ and NW. Some oriental records mention the star group(s), in which an auroral display was visible. These are identified in this paper by italicised names beginning with a capital letter (see Sect. 4 and Table 1); for example, Niu (Ox), (Nan-)Tou (Southern Dipper), Tou-shao (handle of the Northern Dipper), Tzu-wei (Purple Subtlety) and Tzu-wei-kung (Purple Subtlety Palace). Traditional East Asian star groupings differ considerably from occidental constellations, both in size and in the constituent stars. Of the quoted star groups, Niu was part of Capricorn and Nan-Tou was part of Sagittarius, while Tou-shao was part of Ursa Major. Tzu-wei (also equivalent to Tzu-wei-kung) was very extensive and embraced the northern constellations Cepheus, Draco, Ursa Major and Camelopardus.

Another important physical variable is the phase of the Moon at the time of a particular auroral display. In general, faint aurorae are more likely to be detected near new Moon. The phases and elongations of the Moon presented in this and the following section have been calculated using a specially designed computer program. Willis and Stephenson (2000) have provided further background information on all these general matters.

The phase and elongation of the Moon at 16:00 UT (which corresponds approximately to midnight in East Asia) on the night of AD 1128 December 13 were 0.79 and $125^{\circ} \mathrm{W}$, respectively. However, the Moon would not have risen until about 4 hours after sunset (i.e. at about 20:45 LT) on this particular night. Therefore, unless the auroral observations were made early in the evening (before the Moon had risen), the auroral light must have been visible in the presence of strong moonlight. The latter possibility is consistent with the conclusion that the auroral observations on the night of $\mathrm{AD}$ 1128 December 13 were associated with an intense geomagnetic storm.

There is clearly a delay of about five days between the daytime observation (in England) on December 8 of two sunspots on the solar disk and the night-time observation (in Korea) on December 13 of a red auroral display. This time delay is typical of the average delay between central meridian passage of an active solar region (or a halo coronal mass ejection) and the onset of a geomagnetic storm at the Earth (Crooker and Cliver, 1994; Webb et al., 2000; and the references cited in 
Table 1. The oriental auroral records from the middle of AD 1127 to the middle of AD 1129 (from Yau et al., 1995). An asterisk after the date denotes that the appropriate text is included in Fig. 2

1. 1127 Autumn (August 10 - November 5)

[China, Chia-hsing] Chien-yen reign-period, 1st year, autumn. "There was a violet vapour between (the lunar lodges) (Nan-)Tou (Southern Dipper) and Niu (Ox).” (Chia-hsing Hsien-chih, 1) (DC230, YSW186)

2. 1127 September 20

[China, Ying-t'ien] Chien-yen reign-period, 1st year, 8th month, day keng-wu (7). "In the NE direction, there was a red vapour." (Sung-shih, 64) (DC229, KE337, YSW185)

3. 1127 September 22

(i) [China, Ying-t'ien] Chien-yen reign-period, 1st year, 8th month, day jen-shen (9). "This evening, in the NE, there was a red vapour." (Sung-shih, 24)

(ii) [China, Ying-t'ien] Chien-yen reign-period, 1st year, 8th month, day jen-shen (9). "In the NE, there was a red vapour." (Sung-shih, 60) (DC231, YSW187)

(iii) [China, Ying-t'ien] Chien-yen reign-period, 1st year, 8th month, day jen-shen (9). "In the NE direction, there was a red vapour." (Wen-hsien T'ung-kao, 294)

\section{1127 October 17 to $20^{*}$}

[Korea, Songdo] King Injong, 5th year, 9th month, day ting-yu (34). "At night, a red vapour appeared in the SE. On day keng-tzu (37) - 20 October - it was finally extinguished." (Koryo-sa, 53) (DC232-235, YSW188)

\section{1128 February $28^{*}$}

[Korea, Songdo] King Injong, 6th year, 1st month, day hsin-hai (48). "At night, in the N direction, there was a red-white vapour entering Tzu-wei-kung (Purple Subtlety Palace)." (Koryo-sa, 53) (DC236, YSW189)

\section{1128 October 20}

[Korea, Songdo] King Injong, 6th year, 9th month, day ping-wu (43). "A red vapour from the NW passed Tzu-wei (Purple Subtlety) and entered the NE. Also, dark vapours were running into it from the S and N." (Chungbo Munhon Pigo, 8) (DC237, YSW190)

\section{1128 December $13^{*}$}

[Korea, Songdo] King Injong, 6th year, 11th month, day keng-tzu (37). "From the NW to the SW, a red vapour soared and filled the sky." (Koryo-sa, 53) (DC238, YSW 191)

\section{1129 January $10^{*}$}

[Korea, Songdo] King Injong, 6th year, 12th month, day wu-ch'en (5). "At night, a red vapour rose from the NE direction. It passed through Tou-shao (handle of the Northern Dipper) and entered Tzu-wei-kung (Purple Subtlety Palace).” (Koryo-sa, 47, 53) (DC239, YSW192)

these papers).

\section{Evidence for recurrent auroral activity}

All the oriental auroral records between the middle of $\mathrm{AD}$ 1127 and the middle of AD 1129, as included in either the catalogue published by Yau et al. (1995) or the catalogue published by the Beijing Observatory (1988), are reproduced in Table 1. The catalogue published by Yau et al. (1995) includes Chinese, Japanese and Korean auroral records, whereas the catalogue published by the Beijing Observatory (1988) contains only Chinese auroral records. The two-year time interval between the middle of AD 1127 and the middle of AD 1129 has been chosen because there is clear evidence for a 27-day recurrence tendency in auroral activity at both the beginning and the end of this interval (see Table 2). The format used in Table 1 is essentially the same as that adopted by Yau et al. (1995), apart from the introduction of new ref- erence numbers (appropriate to the specified time interval) and the inclusion of relevant place names (i.e. [China, Chiahsing], [China, Ying-t'ien] and [Korea, Songdo]). The modern names for Chia-hsing, Ying-t'ien and Songdo are Jiaxing, Shangqiu and Kaesong, respectively. For each record, the title of the relevant oriental history (in italics) and the appropriate chapter number are given in parentheses [e.g. (Sungshih, 64)]. The letters KE (followed by a reference number) at the end of the appropriate catalogue entry denote an observation derived from the papers by Keimatsu (1970-1976). Similarly, the letters DC (followed by a reference number) denote an observation found in the paper by Dai and Chen (1980). For completeness, the letters YSW (followed by a number) are used to signify the original reference number in the auroral catalogue of Yau et al. (1995).

The auroral record for AD 1128 December 13, which has already been presented and discussed in Sect. 3, is repeated in Table 1 in order to emphasise the recurrent nature of au- 
Table 2. Difference in days between the dates of consecutive distinct oriental auroral events, as extracted from the records in Table 1 (see Sect. 4 for further details). Also shown are the phase and elongation of the Moon at the times of these auroral events

\begin{tabular}{cccc}
$\begin{array}{c}\text { Date of } \\
\text { auroral event } \\
\text { (or range of dates) }\end{array}$ & $\begin{array}{c}\text { Difference } \\
\text { in days } \\
\text { between dates }\end{array}$ & $\begin{array}{c}\text { Phase } \\
(0-1)\end{array}$ & $\begin{array}{c}\text { Moon } \\
\text { Elongation } \\
\left({ }^{\circ} \mathrm{E} \text { or }{ }^{\circ} \mathrm{W}\right)\end{array}$ \\
\hline $\begin{array}{ccc}\text { 1127 September 20-22 } \\
\text { 1127 October 17-20 }\end{array}$ & 27 & $0.97^{*}$ & $160^{\circ} \mathrm{E}^{*}$ \\
1128 February 28 & 134 & $0.82^{*}$ & $131^{\circ} \mathrm{E}^{*}$ \\
1128 October 20 & 235 & 0.13 & $42^{\circ} \mathrm{W}$ \\
1128 December 13 & 54 & 0.27 & $63^{\circ} \mathrm{W}$ \\
1129 January 10 & 28 & 0.79 & $125^{\circ} \mathrm{W}$ \\
\hline
\end{tabular}

The asterisk $\left(^{*}\right)$ signifies that the numerical values for the phase and elongation of the Moon apply to the first date (night) in the quoted interval.

roral activity within the specified two-year interval. The first record in Table 1 is retained, even though the date is imprecise (namely autumn; defined as the 7th, 8th and 9th lunar months, equivalent to the interval August 10 - November 5 in AD 1127). This record (from a local history, rather than an official court compilation) mentions the appearance of a violet aurora near two southern star groups [(Nan-)Tou in Sagittarius and Niu in Capricorn]; these star groups were in the declination range of $-15^{\circ}$ to $-30^{\circ}$ (corresponding to meridian altitudes between $30^{\circ}$ and $45^{\circ}$ ). Hence, this particular aurora was observed to be closer to the southern horizon than the zenith.

It should be noted that the earlier auroral sightings in Table 1 are all from China, whereas the later ones are all from Korea. As discussed in Sect. 2, the political situation in China was very unstable at this period. Although Korea enjoyed relative peace, unfavourable weather conditions may have interfered with observations in either or both countries. However, it should be emphasised that medieval astronomical records from both China and Korea are by no means complete. Chinese and Korean astronomical and other records of this period are no more than summaries of the original material, possibly with the loss of much information.

Table 2 lists the dates of the distinct auroral "events" included in Table 1. For the present purpose, it is assumed that the records for AD 1127 September 20 and 22 refer to the same auroral "event" or, more accurately, the same geomagnetic storm. This simplifying assumption is consistent with the grouping of the four consecutive auroral records for $\mathrm{AD}$ 1127 October 17 to 20 in Dai and Chen (1980) into a single entry (see Table 1) in Yau et al. (1995). The absence of an oriental auroral record for AD 1127 September 21 may not be significant in the context of solar-terrestrial physics. For example, extensive cloud cover might have precluded auroral observations on that date or the original records may have been lost. Hence, the date of the first auroral sighting in a set of consecutive or contiguous sightings is regarded as the "time of onset" of the auroral "event".

On this basis, Table 2 gives the approximate difference in days between the times of onset of consecutive auroral events recorded in the catalogue of Yau et al. (1995); the catalogue published by the Beijing Observatory (1988) does not yield any additional auroral events in the specified two-year interval. It is assumed that each of these six distinct midlatitude auroral events signifies the concurrent existence of a geomagnetic storm, which was sufficiently intense to produce mid-latitude auroral displays in East Asia. Clearly, no incontrovertible information exists on geomagnetic storms that might have occurred at times when ancient oriental auroral observations were precluded by extensive cloud cover. Therefore, with the present assumption, the concomitant list of geomagnetic storms is probably incomplete. Nevertheless, all the time differences presented in Table 2 are almost exact multiples of the 27-day synodic-solar-rotation period (e.g. $134=5 \times 27-1)$, apart from the long interval ( 235 days) between the auroral sightings on AD 1128 February 28 and October 20.

It is now assumed that the results presented in Table 2 actually imply continual ("uninterrupted recurrent") geomagnetic activity every 27 days between AD 1127 September 20 and AD 1128 February 28, and again between AD 1128 October 20 and AD 1129 January 10. With this further assumption, there must have been seven geomagnetic storms in the first "uninterrupted" series of recurrent storms (i.e. AD 1127 September 20, October 17, November 13 and December 10, and AD 1128 January 6, February 2 and February 29, on the basis of an exact 27-day recurrence interval). Likewise, there must have been four geomagnetic storms in the second "uninterrupted" series of recurrent storms (i.e. AD 1128 October 20, November 16 and December 13, and AD 1129 January 9 , again on the basis of an exact 27-day recurrence interval). It should be remembered, however, that corroborative solar evidence exists for just one of the geomagnetic storms (that of AD 1128 December 13) in the second series of recurrent storms. The English sunspot sighting on December 8, of course, provides this corroborative evidence. The lack of any accompanying oriental sunspot records (see Sect. 2), associated with the oriental auroral records presented in Table 1 , suggests that oriental sunspot observations may have been precluded by the lack of suitable atmospheric viewing conditions in East Asia (Willis et al., 1980, 1988). It is clear from various historical records that sunspots were often sighted when the brightness of the Sun was much reduced (e.g. when the Sun was low in the sky, namely just after sunrise or just before sunset, or when haze, mist or smoke prevailed). However, the generally very low frequency of East Asian sunspot sightings, on average only about one per decade, suggests a very incomplete record of these events.

The auroral records presented in Table 1, and hence, the results presented in Table 2, refer to the two-year interval be- 
tween the middle of AD 1127 and the middle of AD 1129. As previously mentioned, this time interval has been selected primarily because there is clear evidence for a 27 -day recurrence tendency in auroral activity at both the beginning and the end of the interval (although the phase changes sometime between AD 1128 February 28 and October 20). However, this two-year time interval is slightly arbitrary in the sense that there is some tentative evidence for recurrent auroral activity before the middle of AD 1127. For example, the date of the (Chinese) auroral observation in the catalogue of Yau et al. (1995) that immediately precedes the first precise date in Table 1 (i.e. the second entry) is AD 1127 April 5. The time difference between AD 1127 April 5 and September 20 is 168 days ( $=6 \times 28$ days). Before AD 1127 April 5 the situation is more problematic, with (Chinese) auroral observations on AD 1127 February 13 and 21. Nevertheless, it is just conceivable that the first series of recurrent storms extended over a time interval as long as approximately 12 synodic solarrotation periods. Similarly, the date of the (Korean) auroral observation that immediately follows the last entry in Table 1 is AD 1129 October 25. The time difference between AD 1129 January 10 and October 25 is 288 days $(=10 \times 29-2)$. Although a period of 29 days is significantly different from a period of 27 days, it is nevertheless still possible that the second series of recurrent storms extended over a time interval appreciably longer than three synodic-solar-rotation periods.

The preceding interpretation of the longer time intervals between successive auroral events (i.e. 168 and 288 days) could be further complicated by the possible presence of a much longer periodicity ( $\gg 27$ days) in the strength of the interplanetary magnetic field. For example, Cane et al. (1998) have reported a 153-day periodicity in both the interplanetary magnetic field strength and the solar wind speed near the Earth during the years 1978-1982. Moreover, these authors have shown that the most significant variations in the longer near-Earth magnetic-field data base (1963-1997), with periods less than 200 days, occurred at 166 and 146 days. If a similar situation prevailed during the interval AD 11271129 , the longer time intervals between successive auroral events might conceivably be associated with such a longer periodicity in the interplanetary magnetic field strength and solar wind speed.

Any attempt to reliably distinguish between a synodicsolar-rotation period of 27 days and one of 28 days (and possibly even one of 29 days) on the basis of such ancient auroral data is likely to prove very difficult. Only one of the ten records included in Table 1 quotes a specific time of night (evening) for the auroral observation. The times of the observations described in the other nine records are uncertain by about at least six hours. This estimate is based on the assumption that each uncertainty is approximately equal to half the corresponding number of hours of darkness. Moreover, the period of synodic solar rotation varies with heliographic latitude. The synodic rotation period, based on observations of sunspots, varies from about 27 days at the solar equator to about 29.5 days at a heliographic latitude of $40^{\circ}$ (Balthasar et al., 1986; Phillips, 1992). These rotation rates, and many others quoted in the literature, have been derived from analyses of the Greenwich Photoheliographic Results: 1873-1976; further background information on these tabulated sunspot observations can be found in the paper by Willis et al. (1996). Unfortunately, however, the tabulated Greenwich data from the twentieth century contain information only on sunspot groups, not individual sunspots. Hence, the rotation rates derived from these data may not be entirely representative of individual sunspots (Howard, 1984, 1996).

Table 2 also gives the phase and elongation of the Moon at 16:00 UT for the six distinct auroral events within the specified two-year interval. If a range of dates is given, the phase and elongation apply to the first date (night) in the interval, as indicated by an asterisk. For example, during the first auroral event, the phase and elongation changed from 0.97 and $160^{\circ}$ E on AD 1127 September 20 to 1.00 and $176^{\circ} \mathrm{W}$ on September 22. Likewise, during the second auroral event, the phase and elongation changed from 0.82 and $131^{\circ} \mathrm{E}$ on $\mathrm{AD} 1127$ October 17 to 0.98 and $164^{\circ} \mathrm{E}$ on October 20. Thus, the first of the six auroral events spanned full Moon, while the second auroral event occurred near full Moon. Moreover, it is clear from the values of phase and elongation presented in Table 2 that two of the remaining four auroral events occurred during one of the gibbous phases of the Moon (i.e. between half and full Moon). The naked-eye detection of four of the six auroral events in the presence of strong moonlight supports the conclusion that all of these mid-latitude auroral events were associated with two series of intense recurrent geomagnetic storms.

\section{Scientific interpretation of the ancient solar and auro- ral observations}

According to present-day understanding, recurrent geomagnetic storms are attributed to corotating interaction regions (CIRs), which tend to occur during the declining phase of the solar cycle (Crooker and Cliver, 1994; Jackson, 1997; Tsurutani and Gonzalez, 1997; Kamide et al., 1998; Gonzalez et al., 1999; Gosling and Pizzo, 1999; Tsurutani and Ho, 1999; and references cited in these papers). The CIRs are created in interplanetary space by high-speed plasma streams emanating from coronal holes, which interact with high-density, low-speed plasma streams associated with the heliospheric current sheet (HCS). During the declining phase of the solar cycle, when polar coronal holes migrate down to lower heliographic latitudes, the streams emanating from these coronal holes apparently "corotate" at approximately 27 -day intervals (as viewed from the Earth). The solar plasma within these corotating streams impinges on the Earth's magnetosphere at regular 27-day intervals, thereby producing recurrent geomagnetic storms (Sheeley et al., 1976, 1977; Burlaga and Lepping, 1977; Crooker and Cliver, 1994; Tsurutani and Gonzalez, 1997; Kamide et al., 1998; Gonzalez et al., 1999; Tsurutani and Ho, 1999).

As noted in Sect. 4, there is evidence that a series of seven recurrent geomagnetic storms occurred in the inter- 
val between AD 1127 September 20 and AD 1128 February 28 . The main evidence is observations of mid-latitude auroral displays recorded in either Chinese or Korean histories for three of the seven inferred geomagnetic storms. Likewise, there is strong evidence that a separate series of four recurrent geomagnetic storms occurred in the interval between AD 1128 October 20 and AD 1129 January 10. The main evidence is observations of mid-latitude auroral displays recorded in Korean histories for three of the four inferred geomagnetic storms. In this latter case, however, one of the three Korean auroral displays occurred five days after the English observation of two large sunspots near the central solar meridian. As also noted in Sect. 4, there is weaker evidence that both series of recurrent storms may have extended over longer time intervals, which spanned more than ten recurrent geomagnetic storms.

In principle, these results can be explained in terms of our present understanding of recurrent geomagnetic activity. For example, several series of recurrent geomagnetic storms have been observed to extend over intervals longer than a year during the declining phases of recent solar cycles (Sheeley et al., 1976, 1977; Burlaga and Lepping, 1977). By analogy with modern observations, it is conceivable that the interval AD 1127-1129 formed part of the declining phase of a medieval solar cycle. However, medieval European auroral observations strongly suggest that this particular interval defined a maximum in the "eleven-year" solar cycle (Siscoe, 1980; see Fig. 7). Tentative conclusions of this type may eventually help in establishing a partial solar-cycle chronology during medieval times. Indeed, the approach adopted here, which is based on current understanding of the solarterrestrial environment, seems rather more appropriate than the somewhat arbitrary assumption of nine sunspot maxima per century (Schove, 1955). Nevertheless, with this latter assumption, Schove $(1955,1983)$ concluded that AD 1129 (possibly AD 1128) was a sunspot-maximum year. [There appear to be major typographical errors in Appendix A (dates of sunspot minima) of the book edited by Schove (1983).]

It is now necessary to consider the implications of recurrent auroral activity at mid-latitudes in East Asia during medieval times. Several authors have suggested that the high medieval occurrence frequency of aurorae over China, Japan and Korea, particularly during the twelfth century, resulted from the north geomagnetic pole being located in the Eastern Hemisphere (probably at East Asian longitudes) during this period (Keimatsu et al., 1968; Siscoe and Verosub, 1983; Fukushima et al., 1987; Oguti, 1993a; Fukushima, 1994; Oguti and Egeland, 1995; Silverman, 1998). It should just be mentioned that the combinatorial calculations performed by Siscoe and Verosub (1983) now need to be repeated in the light of the three simultaneous ("common" or "overlap") medieval auroral observations reported by Willis and Stephenson (2000). However, it is not anticipated that such revised combinatorial calculations will change the main conclusion reached by Siscoe and Verosub (1983). Indeed, the fact that the north geomagnetic pole was located at a high geographic latitude in the Eastern Hemisphere during medieval times has been confirmed quite independently by several authors (Merrill and McElhinny, 1983; Oguti, 1993a; Oguti and Egeland, 1995; Constable et al., 2000).

For the purposes of the present paper, East Asia is defined to be the geographic region that lies within the approximate latitude and longitude ranges $30^{\circ} \mathrm{N}$ to $45^{\circ} \mathrm{N}$ and $100^{\circ} \mathrm{E}$ to $130^{\circ} \mathrm{E}$, respectively. This region encompasses all the historically important cities of China and Korea and thereby includes all the oriental sites at which the medieval auroral observations presented in Table 1 were made. Next, it is assumed that during the interval AD 1127-1129, the north geomagnetic pole was located at a geographic co-latitude of $10^{\circ}$ (i.e. at latitude $80^{\circ} \mathrm{N}$ ), somewhere within a range of geographic longitudes that embraces East Asia (Merrill and McElhinny, 1983; Roberts and Piper, 1989; Constable et al., 2000). This assumption is essentially consistent with conclusions reached quite independently by Siscoe and Verosub (1983) and by Oguti and Egeland (1995).

However, a smaller co-latitude of about $5^{\circ}$ would appear to be more representative of the direct palaeomagnetic evidence based on archaeomagnetic artefacts, lava flows and lake sediments (Merrill and McElhinny, 1983; Constable et al., 2000). For example, the average spherical harmonic models (100year averages) published by Constable et al. (2000) imply that the geographic coordinates of the north geomagnetic pole (dipole axis) were $84.8^{\circ} \mathrm{N}$ and $103.8^{\circ} \mathrm{E}$ in AD 1100. Similar values, namely $84.2^{\circ} \mathrm{N}$ and $110.4^{\circ} \mathrm{E}$, are obtained by considering virtual geomagnetic pole (VGP) positions; the angle of the $95 \%$ confidence cone about the mean axis is $3.5^{\circ}$, using Fisher statistics (C. G. Constable, private communication, 2000). Although based on earlier palaeomagnetic data, Fig. 4.4 in the book by Merrill and McElhinny (1983) yields comparable (approximate) values $\left(85^{\circ} \mathrm{N}, 115^{\circ} \mathrm{E}\right)$ for the north geomagnetic pole. Further research is required to determine the precise position of the north magnetic pole when higher harmonics (non-dipole fields) are included.

In a conventional invariant-magnetic-latitude $(\Lambda)$ - magnetic-local-time (MLT) coordinate system, the instantaneous figure that the band of auroral luminosity inscribes on the upper atmosphere (as seen from a high altitude) has the form of a nearly perfect (circular) annulus (Holzworth and Meng, 1975). This annulus is centred about a point located, on average, approximately $4^{\circ}$ tailward of the instantaneous location of the dipole axis (Holzworth and Meng, 1975; Siscoe, 1991). Under active auroral conditions [e.g. $Q=6$, where $Q$ denotes the quarter-hourly index of geomagnetic activity; see Bartels and Fukushima (1956)], the radius (co-latitude) of the equatorward edge of the offset $\left(\approx 5^{\circ}\right)$ annular auroral oval is just under $25^{\circ}$ (Holzworth and Meng, 1975). Therefore, the geographic latitude of the equatorward edge of the medieval auroral oval is unlikely to have been less than about $50^{\circ}$ at East Asian longitudes, even under active magnetic conditions $(Q=6)$.

This lower limit is largely consistent with results presented by Oguti and Egeland (1995) for the geographic latitude of the equatorward edge of the average subauroral zone over East Asia between 800 and 900 years ago. A lower limit 
of about $50^{\circ}$, for the geographic latitude of the equatorward edge of the auroral oval under active geomagnetic conditions ( $Q=6$ ), is also essentially consistent with the results presented by Legrand and Simon (1989). Based on a special programme of auroral observations undertaken in Western Europe during the interval 1956-1965, these latter authors showed that auroral displays associated with recurrent geomagnetic storms never reached the zenith at invariant magnetic latitudes $(\Lambda)$ less than about $56^{\circ}$. Of course, under extremely active auroral conditions (e.g. $7 \leq Q \leq 11$ ), the medieval auroral oval would have moved equatorwards and hence, would have reached geographic latitudes considerably less than $50^{\circ}$ at East Asian longitudes. However, such extreme auroral conditions are not a salient feature of presentday recurrent geomagnetic storms.

A lower geographic latitude of $50^{\circ}$ for the equatorward edge of the medieval auroral oval at East Asian longitudes under active auroral conditions $(Q=6)$ can now be compared with the geographic latitudes of the sites at which the official Chinese and Korean auroral observations were made (see Table 1). These sites were Ying-t'ien $\left(34.5^{\circ} \mathrm{N}\right)$ and Songdo $\left(38.0^{\circ} \mathrm{N}\right)$, respectively. However, red auroral displays that apparently extend down to the northern horizon are more than $15^{\circ}$ further north than the observing site, assuming a minimum altitude of $250 \mathrm{~km}$ for $630 \mathrm{~nm}$ ("red-line") emission from excited atomic oxygen. Nevertheless, the Chinese and Korean auroral observations between the middle of AD 1127 and the middle of AD 1129 must clearly have been made during intense, or perhaps even during extremely intense (i.e. great), recurrent geomagnetic storms (for which $7 \leq Q \leq 11$ ). This conclusion follows from the fact that three of the eight dated entries in Table 1 (see also Sect. 4) refer to auroral displays that appeared or extended to the south of either Chia-hsing (a small region, approximate geographic latitude $\left.30.5^{\circ} \mathrm{N}\right)$ or Songdo $\left(38.0^{\circ} \mathrm{N}\right)$. Therefore, these ancient recurrent storms would appear to have been far more intense than the recurrent storms that have occurred during the declining phases of recent solar cycles (Tsurutani and Gonzalez, 1997; Kamide et al., 1998; Gonzalez et al., 1999).

From a slightly different viewpoint, auroral isochasms based on auroral data acquired during the interval AD 1700 1942 (Fritz, 1881; Vestine, 1944; see also Chapman, 1957 and Oguti, 1993b) indicate that the expected frequency of bright aurorae at Chia-hsing, Ying-t'ien and Songdo should be no more than about once in twenty years. Even if the medieval north geomagnetic pole was located at a geographic co-latitude of $10^{\circ}$ (i.e. at latitude $80^{\circ} \mathrm{N}$ ), somewhere within a range of longitudes that embraces East Asia $\left(100^{\circ} \mathrm{E}\right.$ to $130^{\circ}$ E), the expected frequency of bright aurorae would increase to no more than about once per decade. Although this conclusion is based partly on the assumption that the level of solar activity was not significantly higher during the twelfth century (Siscoe and Verosub, 1983), it again seems clear that the two series of recurrent geomagnetic storms occurring between the middle of AD 1127 and the middle of AD 1129 must have been intense rather than moderate. This last statement is certainly true according to the conventional classifi- cation scheme for the strength of geomagnetic storms (Tsurutani and Gonzalez, 1997; Gonzalez et al., 1999).

There appears to be only one tenable explanation for the occurrence of at least eleven intense recurrent geomagnetic storms in the interval AD 1127-1129. The combined solar and auroral evidence implies that these intense medieval recurrent geomagnetic storms occurred near sunspot maximum rather than near sunspot minimum, contrary to modern evidence indicating that recurrent geomagnetic storms usually occur during the declining phase of the "eleven-year" solar cycle. As noted in Sect. 2, it is not possible to determine the phase of the solar cycle solely on the basis of the evidence presented in Fig. 1 for the existence of two large sunspots on the solar disk on AD 1128 December 8. However, the presence of a single large sunspot on the solar disk on AD 1129 March 22 and again on April 14 suggests that all these sunspot observations were made near a maximum in the "eleven-year" solar cycle. As noted previously, medieval auroral observations from Europe also strongly suggest that the interval AD 1127-1129 coincided with a maximum in the "eleven-year" solar cycle (Siscoe, 1980; see Fig. 7). Furthermore, the auroral evidence from both East Asia and Europe indicates that solar activity was high throughout the twelfth century (Siscoe, 1980), which essentially spans the interval termed the "Medieval Maximum" (AD 1090-1210) in solar activity on the basis of ${ }^{14} \mathrm{C}$ anomalies in tree rings.

Although the scientific information that can be extracted from medieval records of sunspots and aurorae is inevitably rather limited, studies of the present type definitely help to elucidate how solar activity has varied during historical times. This statement is valid despite the fact that satellite and ground-based measurements made during the past four decades have indicated that there is no simple direct relationship between sunspots and aurorae. For example, it is now known that the different types of geomagnetic storms observed at Earth, namely intense, moderate or weak, depend on the different types of solar-wind plasma, such as coronal mass ejections (CMEs) and corotating interaction regions (CIRs), that impinge on the magnetosphere. Therefore, the type of solar-wind plasma that impinges on the magnetosphere is at least partly responsible for determining the likelihood of observing auroral displays at mid-latitudes. Even for modern measurements, however, quantitative studies of the relationship between intense geomagnetic storms and midlatitude aurorae are complicated by the fact that the auroral electrojet $(A E)$ index and the ring current $\left(D_{s t}\right)$ index are poorly correlated (Russell et al., 2000). Nevertheless, the ultimate goal of the various studies of historical observations of sunspots and aurorae must be to obtain a better physical understanding of the entire Sun-Earth environment at earlier epochs.

\section{Discussion and conclusions}

The salient features of the solar and auroral evidence for an intense recurrent geomagnetic storm during December in 
AD 1128 may be succinctly summarised as follows. Two large sunspots (or dense sunspot groups) were observed from Worcester, England on AD 1128 December 8. There is no other known sunspot record from medieval England. Assuming that the sunspot drawing presented in Fig. 1 was prepared fairly carefully, the angular diameters of the two sunspots were at least about 3 arcmin and 2 arcmin in the northern and southern solar hemispheres, respectively. Likewise, if allowance is made for the considerable variation in the position angle of the Sun's rotational axis with respect to the vertex during the course of the day, as viewed from Worcester, the heliographic latitudes of both sunspots were within the approximate range of $25^{\circ}-35^{\circ}$. Historical oriental records indicate that a single sunspot was observed on AD 1129 March 22 from both Hang-chou in China and Shang-ching in North China. The date of this Chinese sighting of a single sunspot is almost four synodic-solar-rotation periods after the English sighting of two sunspots, which may imply that one of these two sunspots (or dense sunspot groups) persisted for several solar rotations.

Five days after the sighting of two sunspots from Worcester, England, on the night of AD 1128 December 13, a red auroral display was seen from Songdo, Korea (the modern city of Kaesong). The official Korean chronicle (Koryo-sa) refers to a red vapour that "soared and filled the sky" from the north-west to the south-west (Fig. 2). Presumably, this Korean auroral observation was made during the course of an intense geomagnetic storm associated with an active solar region or a corotating interaction region. The configuration of the two large sunspots shown in Fig. 1 implies that they were fairly close to the central meridian on AD 1128 December 8 , at least between noon and sunset. This implication is regarded as circumstantial evidence for the concurrent existence near the central meridian of at least one active solar region. The associated geomagnetic storm is regarded as being intense in the sense that it produced a red auroral display at mid-latitudes in East Asia.

Six distinct East Asian auroral events were recorded between the middle of AD 1127 and the middle of AD 1129. These six events, which are listed in Table 2, are derived from the records presented in Table 1. No other oriental auroral sighting was recorded during this particular two-year time interval. The first distinct event was recorded in Chinese histories and the following five were recorded in Korean histories. The term distinct is used to signify auroral observations separated by a sufficient number of days to imply association with distinct geomagnetic storms. Auroral observations separated by just a few days $(\leq 5)$ are assumed to be associated with the same geomagnetic storm. The differences in days between the dates of the distinct auroral events listed in Table 2 are almost exact multiples of the synodicsolar-rotation period (27 days), apart from the long interval (235 days) between AD 1128 February 28 and October 20. The phase of the 27-day recurrence effect in auroral activity must have changed during this long interval. Assuming that the auroral evidence implies continual recurrent geomagnetic activity every 27 days between AD 1127 September 20 and
AD 1128 February 28 and again between AD 1128 October 20 and AD 1129 January 10, there must have been seven recurrent geomagnetic storms in the first interval and four in the second interval. As noted in Sect. 4, there is tentative auroral evidence that both series of recurrent storms may have extended over even longer time intervals.

Neither the combined solar and auroral evidence for an individual intense (recurrent) geomagnetic storm during December in AD 1128 (Sects. 2 and 3), nor the associated auroral evidence for two series of intense recurrent geomagnetic storms during the interval AD 1127-1129 (Sect. 4), provides completely unambiguous information on the phase of the "eleven-year" solar cycle at this time. From a purely statistical viewpoint, the estimated sizes $(\approx 2-3 \mathrm{arcmin})$ of the two sunspots observed on AD 1128 December 8 typify the situation that prevails near sunspot maximum. Conversely, the estimated range of latitudes $\left(\approx 25^{\circ}-35^{\circ}\right)$ of both the northern and southern sunspots typifies the situation that prevails soon after sunspot minimum (Sect. 2). Many notable exceptions to these average statistical properties have been reported during the past 150 years, however, on the basis of direct photographic evidence of the positions and sizes of sunspots on the solar disk.

Nevertheless, the additional observation of a single sunspot on AD 1129 March 22 from both Hang-chou in China and Shang-ching in North China (Sect. 2), suggests that these solar observations are more likely to have been made near sunspot maximum. This conclusion follows from the fact that the Chinese observations occurred almost exactly four synodic-solar-rotation periods after the observation of two large sunspots from Worcester, England on AD 1128 December 8. Therefore, one of the two large sunspots observed from Worcester may have survived for a further 104 days to be observed on AD 1129 March 22 from both Hang-chou and Shang-ching, which implies that solar activity was likely to have been high during AD 1128 and 1129. Moreover, a different sunspot was observed from Hang-chou on AD 1129 April 14 (Sect. 2), which again suggests that solar activity was high at this particular time. Finally, medieval European auroral evidence corroborates the conclusion that the end of the second decade of the twelfth century coincided with a maximum in the "eleven-year" solar cycle (Sect. 5).

According to present-day theory, based on contemporary ground-based and satellite measurements during the last few decades, recurrent geomagnetic storms tend to occur during the declining phase of the solar cycle. Moreover, their strength is usually classified as being moderate, or even weak, rather than intense. However, the strength of the medieval recurrent geomagnetic storms occurring between about the middle of AD 1127 and the middle of AD 1129 must have been intense rather than moderate or weak. This conclusion follows from the fact that the auroral light was observed to the south of Chia-hsing (approximate geographic latitude $30.5^{\circ} \mathrm{N}$ ) for the first (imprecisely-dated) auroral record listed in Table 1 (AD 1127 August 10 - November 5). Similarly, the auroral light was observed to extend to the south of Songdo (geographic latitude $38.0^{\circ} \mathrm{N}$ ) for two of the six distinct 
auroral events listed in Table 2 (AD 1127 October 17-20 and AD 1128 December 13).

However, some allowance must be made for the likely medieval orientation of the geomagnetic field, since several authors have suggested that the north geomagnetic pole was located within a range of longitudes that embraces East Asia $\left(100^{\circ} \mathrm{E}\right.$ to $\left.130^{\circ} \mathrm{E}\right)$ during the twelfth century (Sect. 5). Even if the north geomagnetic pole was at a co-latitude of about $10^{\circ}$ (i.e. at latitude $80^{\circ} \mathrm{N}$ ), the recurrent geomagnetic storms occurring during the interval AD 1127-1129 must still have been intense, or even very intense, to have produced some auroral displays that extended to the south of Chia-hsing or Songdo. Moreover, this conclusion regarding the likely strength of the recurrent geomagnetic storms during the interval AD 1127-1129 would be even more convincing if the north geomagnetic pole was at a co-latitude of only about $5^{\circ}$. A smaller co-latitude of $5^{\circ}$ during the twelfth century would appear to be more consistent with the recent palaeomagnetic evidence (see Sect. 5). Therefore, the two series of intense recurrent geomagnetic storms occurred near a medieval maximum in the "eleven-year" solar cycle. An immediate consequence of this conclusion is that the level of solar activity must have been unusually high at the end of the second decade of the twelfth century.

Acknowledgements. The authors thank the President and Fellows of Corpus Christi College, Oxford, for permission to publish Fig. 1. They also thank two referees, whose constructive comments have resulted in several important clarifications.

Topical Editor G. Chanteur thanks R. Gendrin and G. Siscoe for their help in evaluating this paper.

\section{References}

Balthasar, H., Vázquez, M., and Wöhl, H., Differential rotation of sunspot groups in the period from 1874 through 1976 and changes of the rotation velocity within the solar cycle, Astron. Astrophys., 155, 87-98, 1986.

Bartels, J. and Fukushima, N., Ein Q-Index für die erdmagnetische Aktivität in viertelstündlichen Intervallen, Abhandlungen der Akademie der Wissenschaften in Göttingen, MathematischPhysikalische Klasse, Sonderheft Nr. 2, Vandenhoeck \& Ruprecht, Göttingen, 1956.

Beijing Observatory (Ed.), Zhongguo Gudai Tianxiang Jilu Zongji (A Union Table of Ancient Chinese Records of Celestial Phenomena) (in Chinese), Kexue Jishi Chubanshe, Kiangxu, pp. 2760, 1988.

Burlaga, L. F. and Lepping, R. P., The causes of recurrent geomagnetic storms, Planet. Space Sci., 25, 1151-1160, 1977.

Cane, H. V., Richardson, I. G., and von Rosenvinge, T. T., Interplanetary magnetic field periodicity of $\sim 153$ days, Geophys. Res. Lett., 25, 4437-4440, 1998.

Chapman, S., The aurora in middle and low latitudes, Nature, 179, 7-11, 1957.

Constable, C. G., Johnson, C. L., and Lund, S. P., Global geomagnetic field models for the past 3000 years: transient or permanent flux lobes? Phil. Trans. R. Soc. Lond., A 358, 991-1008, 2000.

Crooker, N. U. and Cliver, E. W., Postmodern view of M-regions, J. Geophys. Res., 99, 23383-23390, 1994.
Dai Nian-zu and Chen Mei-dong, Historical auroral data from China, Korea and Japan from the legendary period to A.D. 1747 (in Chinese), Kejishiwenji, 6, 87-146, 1980.

Darlington, R. R., McGurk, P., and Bray, J., The Chronicle of John of Worcester, Volume II, Clarendon Press, Oxford, 1995.

Fritz, H., Das Polarlicht, Brockhaus, Leipzig, 1881.

Fukushima, N., Some topics and historical episodes in geomagnetism and aeronomy, J. Geophys. Res., 99, 19113-19142, 1994.

Fukushima, N., Egeland, A., Jin, L.-Z., Liu, Q.-L., Silverman, S. M., and Teboul, M., Secular variation of the geomagnetic axis in historic time known from the comparison of ancient records of aurorae observed in the Occident and Orient, Proceedings of IAGA Symposium on Space-Time Structure of the Geomagnetic Field (held at Wittenberg, Germany, September 1986), Report 21, Heinrich-Hertz-Institute, Berlin, pp. 55-58, 1987.

Gonzalez, W. D., Tsurutani, B. T., and Clúa de Gonzalez, A. L., Interplanetary origin of geomagnetic storms, Space Sci. Rev., 88, 529-562, 1999.

Gosling, J. T. and Pizzo, V. J., Formation and evolution of corotating interaction regions and their three dimensional structure, Space Sci. Rev., 89, 21-52, 1999.

Holzworth, R. H. and Meng, C.-I., Mathematical representation of the auroral oval, Geophys. Res. Lett., 2, 377-380, 1975.

Howard, R., Solar rotation, Ann. Rev. Astron. Astrophys., 22, 131155,1984

Howard, R. F., Solar active regions as diagnostics of subsurface conditions, Ann. Rev. Astron. Astrophys., 34, 75-109, 1996.

Jackson, B. V., Heliospheric observations of solar disturbances and their potential role in the origin of geomagnetic storms, in Magnetic Storms Eds. B. T. Tsurutani, W. D. Gonzalez, Y. Kamide, and J. K. Arballo, Geophysical Monograph 98, American Geophysical Union, Washington DC, USA, pp. 59-76, 1997.

Kamide, Y., Baumjohann, W., Daglis, I. A., Gonzalez, W. D., Grande, M., Joselyn, J. A., McPherron, R. L., Phillips, J. L., Reeves, E. G. D., Rostoker, G., Sharma, A. S., Singer, H. J., Tsurutani, B. T., and Vasyliunas, V. M., Current understanding of magnetic storms: storm-substorm relationships, J. Geophys. Res., 103, 17705-17728, 1998.

Keimatsu, M., A chronology of aurorae and sunspots observed in China, Korea and Japan, Annals of Science, Kanazawa University, Part I, 7, 1-10, 1970; Part II, 8, 1-16, 1971; Part III, 9, 1-36, 1972; Part IV, 10, 1-32, 1973; Part V, 11, 1-36, 1974; Part VI, 12, 1-40, 1975; Part VII, 13, 1-32, 1976.

Keimatsu, M., Fukushima, N., and Nagata, T., Archaeo-aurora and geomagnetic secular variation in historic time, J. Geomagn. Geoelectr., 20, 45-50, 1968.

Legrand, J.-P. and Simon, P. A., Solar cycle and geomagnetic activity: a review for geophysicists. Part I. The contributions to geomagnetic activity of shock waves and of the solar wind, Ann. Geophysicae, 7, 565-578, 1989.

Matsushita, S., Ancient aurorae seen in Japan, J. Geophys. Res., 61 , 297-302, 1956.

McGurk, P., The Chronicle of John of Worcester, Volume III, Clarendon Press, Oxford, 1998.

Merrill, R. T. and McElhinny, M. W., The Earth's Magnetic Field: Its History, Origin and Planetary Perspective, Academic Press, London, 1983.

Oguti, T., The auroral zone in historic times - the northern UK was in the auroral zone 300 years ago, J. Geomagn. Geoelectr., 45, 231-242, 1993a.

Oguti, T., A note on the auroral frequency charts by Fritz and Vestine, J. Geomagn. Geoelectr., 45, 449-454, 1993b. 
Oguti, T. and Egeland, A., Auroral occurrences in Norwegian archives, J. Geomagn. Geoelectr., 47, 353-359, 1995.

Phillips, K. J. H., Guide to the Sun, Cambridge University Press, Cambridge, 1992.

Roberts, N. and Piper, J. D. A., A description of the behaviour of the Earth's magnetic field, in Geomagnetism, Volume 3, Ed. J. A. Jacobs, Academic Press, London, pp. 163-260, 1989.

Royal Greenwich Observatory, Sunspot and Geomagnetic-Storm Data Derived from Greenwich Observations, 1874-1954, H. M. Stationery Office, London, 1955.

Russell, C. T., Lu, G., and Luhmann, J. G., Lessons from the ring current injection during the September 24, 25, 1998 storm, Geophys. Res Lett., 27, 1371-1374, 2000.

Schove, D. J., The sunspot cycle, 649 B.C. to A.D. 2000, J. Geophys. Res., 60, 127-146, 1955.

Schove, D. J., The sunspot cycle, 649 B.C. to A.D. 2000, (reprinted) in Sunspot Cycles, Ed. D. J. Scove, Hutchinson Ross Publishing Company, Stroudsburg, Pennsylvania, pp. 149-168, 1983.

Sheeley, N. R., Harvey, J. W., and Feldman, W. C., Coronal holes, solar wind streams, and recurrent geomagnetic disturbances: 1973-1976, Solar Phys., 49, 271-278, 1976.

Sheeley, N. R., Asbridge, J. R., Bame, S. J., and Harvey, J. W., A pictorial comparison of interplanetary magnetic field polarity, solar wind speed, and geomagnetic disturbance index during the sunspot cycle, Solar Phys., 52, 485-495, 1977.

Silverman, S., Early auroral observations, J. Atmos. Solar-Terr. Phys., 60, 997-1006, 1998.

Siscoe, G. L., Evidence in the auroral record for secular solar variability, Rev. Geophys. Space Phys., 18, 647-658, 1980.

Siscoe, G. L., What determines the size of the auroral oval? in Auroral Physics, Eds. C.-I. Meng, M. J. Rycroft, and L. A. Frank, Cambridge University Press, Cambridge, pp. 159-175, 1991.

Siscoe, G. L. and Verosub, K. L., High medieval auroral incidence over China and Japan: implications for the medieval site of the geomagnetic pole, Geophys. Res. Lett., 10, 345-348, 1983.

Stephenson, F. R., Historical Eclipses and Earth's Rotation, Cambridge University Press, Cambridge, 1997.

Stephenson, F. R. and Willis, D. M., The earliest drawing of sunspots, Astronomy \& Geophysics, 40, 6.21-6.22, 1999.

Tsurutani, B. T. and Gonzalez, W. D., The interplanetary causes of magnetic storms: a review, in Magnetic Storms, Eds. B. T. Tsurutani, W. D. Gonzalez, Y. Kamide, and J. K. Arballo, Geophysical Monograph 98, American Geophysical Union, Washington DC, USA, pp. 77-89, 1997.

Tsurutani, B. T. and Ho, C. M., A review of discontinuities and Alfvén waves in interplanetary space: Ulysses results, Rev. Geophys., 37, 517-541, 1999.

Vestine, E. H., The geographic incidence of aurora and magnetic disturbance, northern hemisphere, Terr. Magn. Atmosph. Electr., 49, 77-102, 1944.

Webb, D. F., Cliver, E. W., Crooker, N. U., Cyr, O. C. St., and Thompson, B. J., Relationship of halo coronal mass ejections, magnetic clouds, and magnetic storms, J. Geophys. Res., 105, 7491-7508, 2000

Willis, D. M. and Stephenson, F. R., Simultaneous auroral observations described in the historical records of China, Japan and Korea from ancient times to AD 1700, Ann. Geophysicae, 18, $1-10,2000$.

Willis, D. M., Easterbrook, M. G., and Stephenson, F. R., Seasonal variation of oriental sunspot sightings, Nature, 287, 617-619, 1980.

Willis, D. M., Doidge, C. M., Hapgood, M. A., Yau, K. K. C., and Stephenson, F. R., Seasonal and secular variations of the oriental sunspot sightings, in Secular Solar and Geomagnetic Variations in the Last 10,000 Years, Eds. F. R. Stephenson and A. W. Wolfendale, Kluwer Academic Publishers, Dordrecht, The Netherlands, pp. 187-202, 1988.

Willis, D. M., Davda, V. N., and Stephenson, F. R., Comparison between Oriental and Occidental sunspot observations, Q. J. R. Astron. Soc., 37, 189-229, 1996.

Wittmann, A. D. and Xu, Z. T., A catalogue of sunspot observations from 165 BC to AD 1684, Astron. Astrophys. Suppl. Ser., 70, 83-94, 1987.

Yau, K. K. C. and Stephenson, F. R., A revised catalogue of Far Eastern observations of sunspots (165 BC to AD 1918), Q. J. R. Astron. Soc., 29, 175-197, 1988.

Yau, K. K. C., Stephenson, F. R., and Willis, D. M., A Catalogue of Auroral Observations from China, Korea and Japan (193 B.C. - A.D. 1770), Rutherford Appleton Laboratory Technical Report RAL-TR-95-073, December 1995. 